\title{
Respiratory phase and visual signal detection
}

\author{
JERRY E. FLEXMAN* \\ Department of Psychology
}

\author{
and \\ ROBERT G. DEMAREE and D. DWAYNE SIMPSON \\ Institute of Behavioral Research \\ Texas Christian University, Fort Worth, Texas 76129
}

\begin{abstract}
Previous studies have implicated respiration as a source of intra-S variation in visual signal detection tasks. In the present study, pneumographic respiration records were obtained on 22 female undergraduates during a visual signal detection task. The analysis of signal detection with respect to respiration phase showed that signals presented during exhalation were detected more frequently than those presented during inhalation. These findings suggest that the intra-S variation in signal detection performance may be partially accounted for by respiratory behavior at the moment of signal presentation.
\end{abstract}

A basic consideration in information processing and signal detection theories is that the performance of an $\mathrm{O}$ is apt to fluctuate in an unpredictable and random-like manner from one signal presentation to another. Such fluctuations are typically attributed to moment-to-moment changes in the "internal state" of the $\mathrm{O}$ and are accepted as intra- $S$ variation (a source of error) in performance. Recent studies have been reported, however, which indicate an apparent linkage between the autonomic nervous system and somatic motor responses (Lacey \& Lacey, 1974; Obrist, Webb, Sutterer \& Howard, 1970; Saxon, 1970). These findings suggest that a metabolic dependency may exist between some somatic events and physiological functions, which partially accounts for performance fluctuations of individuals in certain situations. In particular, it has been suggested that heart rate, blood pressure, and respiration may be related to the performance of certain kinds of tasks.

The implication of respiration as a source of intra-S variation in performance involving detection of momentary stimuli has been noted in a previous study by Flexman and Demaree (1972). They found that signal detections of visual stimuli appeared to be more probable during exhalation phases of respiration than during inhalation. The purpose of the present investigation was to substantiate these preliminary findings and to examine in more detail the relationship between respiratory phase and performance in a visual detection task.

*Present address: Department of Psychology, Boston Veterans Administration Hospital, Boston, Massachusetts 02130.

\section{METHOD}

\section{Subjects}

Twenty-two female students from undergraduate introductor psychology classes at Texas Christian University served as Ss.

\section{Apparatus}

Respiration was recorded with a bellows pneumograph attached around the chest on a level immediately below the ziphoid process. Respiration, stimulus events, and $S$ responses were recorded on a Narco Bio-Systems Physiograph Six, which was located with task programming equipment in a room separated from the $S$ chamber by a wall containing a one-way glass and a small projection window covered by clear Plexiglas. The $S$ was seated in a modified dental chair with a fixed headrest which served to limit head movement. The chair faced a $40 \times 40 \mathrm{in}$. projection screen located approximately $7 \mathrm{ft}$ away. On the right armrest, at fingertip level. were four response buttons; one was positioned in each quadrant of a small response panel. A background white noise was used to mask noise from the programming equipment.

The signal detection task was presented with the simultaneous use of two projectors. A Kodak AF projector was used to provide background illumination and to project cross hairs for demarcation of the viewing area into four equal-sized quadrants. The second projector (a Kodak programmable Carousel) was used to present the signal detection stimuli. A normally open Alpha-Wollensack shutter was mounted on the lens of the second projector and the adjustable $F$ stop served to control stimulus brightness. Shutter speed of the projector for presenting signals was controlled by a Hunter timer set at $.01 \mathrm{sec}$.

The stimulus was a circular spot of light (approximately 9 in. in diam), which appeared on the screen in one of the four quadrants. The background light and the signal-detection stimuli were projected through a yellow stage gel. The stimuli were presented randomly with respect to both the quadrant and the time interval between signals. Interstimulus intervals varied from 3 to $8 \mathrm{sec}$ and were under the control of a paper tape reader.

\section{Procedure}

The experimental session lasted approximately $1 \mathrm{~h}$. When the $S$ arrived, the recording sensor was attached and its purpose briefly explained. Approximately $10 \mathrm{~min}$ were allowed for adjusting the 
physiograph and $S$ habituation. The task was then explained and a sample trial was given. The $S$ was told that signals would be presented (at random intervals) throughout the duration of each trial period in any one of the four quadrants, and that she should indicate each time a signal was detected by depressing the key on the response panel which corresponded to the quadrant location of the signal.

By adjusting the brightness control of the shutter, the approximate $50 \%$ threshold level was ascertained by the method of limits. The first of five 4-min trials (with 2 -min intertrial intervals) was then initiated. Each trial included approximately 44 signal presentations at 3- to 8-sec intervals. The background light was extinguished between trials and $\mathrm{Ss}$ were instructed that the onset of the background light signaled the start of the next trial.

After the background was illuminated, a $30-\mathrm{sec}$ light adaptation period was allowed before the first signal of the new trial was presented. In order to maintain the signal near the $50 \%$ detection threshold, and thus have maximum uncertainty of detection outcome, adjustments were sometimes made in the brightness level of the signal during the task. More specifically, when a S detected five successive signals or missed five successive signals, the brightness level of the signal was either decreased or increased ilightly.

\section{RESULTS}

To examine the association between respiratory phase and signal detection, the respiration cycle was divided into the inhalation phase and the exhalation phase. The inhalation phase extended from the end of exhalation pause to peak inhalation (the point of inhalation-to-exhalation transition). The exhalation phase extended from peak inhalation (marking the beginning of exhalation) to the end of the exhalation pause (marked by the initiation of the subsequent inhalation). Because there was no clear boundary in the respiration records between the expiration slope and the juxtaposed pause, the exhalation phase consisted of both segments. Any signals occurring at the junction between phases were eliminated from the analyses; this resulted in the exclusion of two to five signals for each $S$.

Detection responses were scored correct if a keypress was made within $3 \mathrm{sec}$ of the signal presentation and properly identified the quadrant in which the signal appeared. Response errors which occurred were generally errors of omission (undetected signals); responses when no signal was presented and keypresses for a different quadrant than the one in which the signal appeared were highly infrequent.

The total number of signals presented and signals detected during inhalation and exhalation phases were determined for each $\mathrm{S}$ across all five trials. These data, along with the percentages of signals detected in each phase are shown in Table 1. Due to the longer duration of time normally spent in exhalation than in inhalation, it is observed that the number of randomly presented signals occurring during exhalation ranged from 86 to 160 , while only 31 to 78 occurred during inhalation. Comparisons of the percentages of signals detected in each of the two phases, however, revealed that all Ss exhibited higher detection rates during exhalation than during inhalation. Overall, $55.9 \%$ of the signals presented during exhalation were detected, compared to $33.4 \%$ during inhalation.

Table 1

Number of Signal Detection Stimuli Presented and Detected During Inhalation and Exhalation Phases for Each Subject and Chi-Square Values

\begin{tabular}{|c|c|c|c|c|c|c|c|}
\hline \multirow[b]{2}{*}{$\mathbf{S}$} & \multicolumn{3}{|c|}{ Inhalation } & \multicolumn{3}{|c|}{ Exhalation } & \multirow[b]{2}{*}{$\begin{array}{c}\text { Chi } \\
\text { Square }\end{array}$} \\
\hline & $\begin{array}{l}\text { Number } \\
\text { Presented }\end{array}$ & $\begin{array}{l}\text { Number } \\
\text { Detected }\end{array}$ & $\begin{array}{l}\text { Percent } \\
\text { Detected }\end{array}$ & $\begin{array}{l}\text { Number } \\
\text { Presented }\end{array}$ & $\begin{array}{l}\text { Number } \\
\text { Detected }\end{array}$ & $\begin{array}{l}\text { Percent } \\
\text { Detected }\end{array}$ & \\
\hline 1 & 37 & 14 & 38 & 154 & 93 & 60 & $6.16^{*}$ \\
\hline 2 & 77 & 22 & 29 & 125 & 75 & 60 & $18.16^{* *}$ \\
\hline 3 & 46 & 20 & 43 & 134 & 80 & 60 & 3.65 \\
\hline 4 & 50 & 15 & 30 & 151 & 92 & 61 & $14.43^{* *}$ \\
\hline 5 & 64 & 25 & 39 & 143 & 73 & 51 & 2.55 \\
\hline 6 & 49 & 16 & 33 & 160 & 98 & 61 & $12.37^{* *}$ \\
\hline 7 & 74 & 26 & 35 & 131 & 76 & 58 & $7.96 *$ \\
\hline 8 & 46 & 9 & 20 & 150 & 72 & 48 & $11.74^{* *}$ \\
\hline 9 & 64 & 18 & 28 & 140 & 75 & 54 & $11.47^{* *}$ \\
\hline 10 & 61 & 23 & 38 & 142 & 88 & 62 & $10.47^{* *}$ \\
\hline 11 & 78 & 20 & 26 & 131 & 68 & 52 & $14.31 * *$ \\
\hline 12 & 59 & 24 & 41 & 127 & 70 & 55 & 3.36 \\
\hline 13 & 42 & 17 & 40 & 155 & 88 & 57 & 3.53 \\
\hline 14 & 31 & 8 & 26 & 119 & 67 & 56 & $9.15 * *$ \\
\hline 15 & 58 & 12 & 21 & 103 & 44 & 43 & $7.94 * *$ \\
\hline 16 & 33 & 9 & 27 & 86 & 53 & 62 & $11.28 * *$ \\
\hline 17 & 52 & 19 & 37 & 140 & 84 & 60 & $8.39 * *$ \\
\hline 18 & 54 & 25 & 46 & 135 & 75 & 56 & 1.33 \\
\hline 19 & 44 & 14 & 32 & 144 & 74 & 51 & $5.18^{*}$ \\
\hline 20 & 64 & 23 & 36 & 135 & 70 & 52 & $4.42^{*}$ \\
\hline 21 & 45 & 18 & 40 & 152 & 82 & 54 & 2.70 \\
\hline 22 & 59 & 20 & 34 & 142 & 80 & 56 & $8.40^{* *}$ \\
\hline Total & 1187 & 397 & $33.4 \%$ & 2999 & 1677 & $55.9 \%$ & \\
\hline
\end{tabular}

$* p<.05$

$* * p<.005$ 
Individual chi-square analyses, shown in Table 1, revealed that 16 of the 22 Ss detected significantly more signals $(\mathrm{p}<.05)$ during exhalation than during inhalation. Another way of looking at these results is to consider the 22 chi-square values, with $1 \mathrm{df}$ each, as independent replications of the study. Under the null hypothesis, the sum of these chi-square values is distributed as chi square with $\mathrm{df}=22$. This result was also highly significant $\left(\chi^{2}=178.95, \mathrm{p}<.005\right)$.

\section{DISCUSSION}

The results provide confirmatory evidence that a relationship exists between respiratory phase and the visual detection of momentary stimuli, since individuals were more likely to detect a signal if it was presented during the exhalation phase of respiration than during the inhalation phase. The data suggest, therefore, that the level of attention required for optimal performance in a signal detection task may be interfered with during inhalation and that an optimal physiological state may exist during which time the probability of detecting a threshold level stimulus is improved.

Obrist et al (1970) have reported that prior to the respond signal onset in a simple (fixed foreperiod) reaction time task, as well as during the anticipation of an aversive shock stimulus in a classical conditioning paradigm, there is a general decrease in physiological activity which includes a slowing (and in some instances a complete temporary cessation) of respiration. The magnitude of the decrease in activity also tends to be directly associated with better task performance. These authors concluded that task-irrelevant activity is apparently attenuated prior to the task response, thus reducing the amount of neural interference interacting with expedient task performance. The results of the present study are consistent with the conclusions of Obrist et al (1970), assuming that exhalation is the less active phase of respiration. Indeed, it has been reported by Crosby, Humphrey, and Lauer (1962) that there is more neurological activity during inhalation than during exhalation. Since the level of this activity should also vary during different parts of the exhalation phase, however, it would be of further interest to examine signal detection rates with reference to smaller segments of exhalation.

In conclusion, the present results indicate that part of the intra-S variation in the performance of visual signal detection tasks, in which anticipatory cues to signal presentations are not present, is related to the respiratory phase. The findings of previous research which implicate respiration as a significant source of moment-to-moment variation in performance were therefore supported.

\section{REFERENCES}

Crosby, E. C., Humphrey, T., \& Lauer, E. W. Correlative anatomy of the nervous system. New York: MacMillan, 1962.

Flexman, J. E., \& Demaree, R. G. Physiological correlates of signal detection. Paper presented at the meeting of the Southwestern Psychological Association, Oklahoma City, April 1972.

LACEY, B. C., \& LACEY, J. I. Studies of heart rate and other bodily processes in sensorimotor behavior. In P. A. Obrist, A. Black. J. Brenner, and L. DiCara (Eds.), Cardiovascular psycho. physiology: Current issues in response mechanisms, biofeedback and methodology. Chicago: Aldine-Atherton, 1974.

Obrist, P. A., Webb, R. A., Sútrerer, J. R., \& Howard, J. L. The cardiac-somatic relationship: Some reformulations. Psychophysiology, 1970, 6, 569-587.

SAXon, S. A. Detection of near threshold signals during four phases of the cardiac cycle. Alabama Journal of Medical Sciences, 1970, 7, 427-430.

(Received for publication January 11, 1974; revision accepted June 11, 1974.) 